\title{
VALIDATION OF DEMS DERIVED FROM HIGH RESOLUTION SAR DATA: A CASE STUDY ON BARCELONA
}

\author{
Umut G. Sefercik $^{\text {a, } 1}$, Alexander Schunert ${ }^{b}$, Uwe Soergel ${ }^{b}$, Kinichiro Watanabe ${ }^{\mathrm{c}}$ \\ ${ }^{a}$ Bulent Ecevit University, Zonguldak, Turkey - \\ ugsefercik@hotmail.com \\ ${ }^{\mathrm{b}}$ Institute of Photogrammetry and GeoInformation (IPI), Leibniz Universität Hannover, Hannover, Germany - \\ (schunert, soergel)@ipi.uni-hannover.de \\ ${ }^{c}$ Geospatial Information Authority of Japan - \\ watakin@gsi.go.jp
}

Commission VII, WG VII/2

Key Words: TerraSAR-X, DEM, Generation, Validation, Accuracy, Visualization

\begin{abstract}
:
In recent years, Synthetic Aperture Radar (SAR) data have been widely used for scientific applications and several SAR missions were realized. The active sensor principle and the signal wavelength in the order of centimeters provide all-day and all-weather capabilities, respectively. The modern German TerraSAR-X (TSX) satellite provides high spatial resolution down to one meter.. Based on such data SAR Interferometry may yield high quality digital surface models (DSMs), which includes points located on $3 \mathrm{~d}$ objects such as vegetation, forest, and elevated man-made structures. By removing these points, digital elevation model (DEM) representing the bare ground of Earth is obtained. The primary objective of this paper is the validation of DEMs obtained from TSX SAR data covering Barcelona area, Spain, in the framework of a scientific project conducted by ISPRS Working Group VII/2 "SAR Interferometry" that aims the evaluation of DEM derived from data of modern SAR satellite sensors. Towards this purpose, a DSM was generated with $10 \mathrm{~m}$ grid spacing using TSX StripMap mode SAR data and converted to a DEM by filtering. The accuracy results have been presented referring the comparison with a more accurate $(10 \mathrm{~cm}-1 \mathrm{~m})$ digital terrain model (DTM) derived from large scale photogrammetry. The results showed that the TSX DEM is quite coherent with the topography and the accuracy is in between $\pm 8-10 \mathrm{~m}$. As another application, the persistent scatterer interferometry (PSI) was conducted using TSX data and the outcomes were compared with a 3d city model available in Google Earth, which is known to be very precise because it is based on LIDAR data. The results showed that PSI outcomes are quite coherent with reference data and the RMSZ of differences is around $2.5 \mathrm{~m}$.
\end{abstract}

\section{INTRODUCTION}

Digital Surface Models (DSMs) are the basic components for three dimensional (3D) representation of the Earth surface comprising vegetation, forest and human made structures above bare topography. DSMs can be generated by wide range of techniques from ground survey to space-borne remote sensing. Of course, those DSMs feature different properties in terms of coverage, accuracy, and cost per area. That's why the most suitable one should be selected considering the needs of applications. For instance, if large land coverage is required and $0.5 \mathrm{~m}-10 \mathrm{~m}$ accuracy is enough, space-borne remote sensing may be the best technique (considering USGS standards). The most common techniques for DSM generation from satellite imagery are optical stereoscopy and interferometric synthetic aperture radar (InSAR). InSAR is conducted either in single-pass or repeat-pass mode. It's a matter of common knowledge that Shuttle Radar Topography Mission (SRTM) is among the most striking success stories of radar remote sensing (Rabus et al, 2003). The SAR data gathered during this shuttle mission in the year 2000 were processed to a DEM of almost global coverage, which is the best elevation model for many regions of the world and widely used still today.

The primary objective of this paper is the validation of high resolution DEMs obtained by repeat-pass interferometry. A DSM with $10 \mathrm{~m}$ grid interval was generated from TerraSAR-X (TSX) StripMap mode ( $3 \mathrm{~m}$ resolution) data at Barcelona test site applying standard InSAR processing. Afterwards, the DSMDEM conversion was performed by optimal filtering method (Jacobsen, 2003). For verification a common procedure was employed and more accurate $(10 \mathrm{~cm}-1 \mathrm{~m})$ digital terrain model (DTM) produced by photogrammetry were used as reference (Lin et al., 1994).

We believe it is an interesting scientific topic to evaluate the quality of DEMs derived from SAR data of modern satellite sensors. Twelve international groups of scientists participate in a long term project managed by ISPRS Working Group VII/2. The groups apply different techniques for DEM generation (Radargrammetry, standard InSAR, multi-baseline InSAR etc.) and the results shall be validated against high quality ground truth. Furthermore, the DEM derived by the various approaches are mutually compared to investigate their pros and cons. The DLR agreed to provide more than 100 TSX images of several urban areas for the project. 


\section{TEST FIELD}

Barcelona is the capital of Catalonia, Spain, and densely populated with about 1.6 million inhabitants of the city and 4 million in the region. The evaluation was conducted for two areas separately: "Large Area" covers $32.9 \mathrm{~km}$ Range $(\mathrm{Rg}) \times 56.6 \mathrm{~km}$ Azimuth $(\mathrm{Az})$ including varied terrain conditions (This area overlaps with the limits of TSX image-pair). "Urban Area" is a subset of large area covering the urban area of Barcelona. Figure 1 shows the Google image of test site and the frequency distribution of terrain inclination.

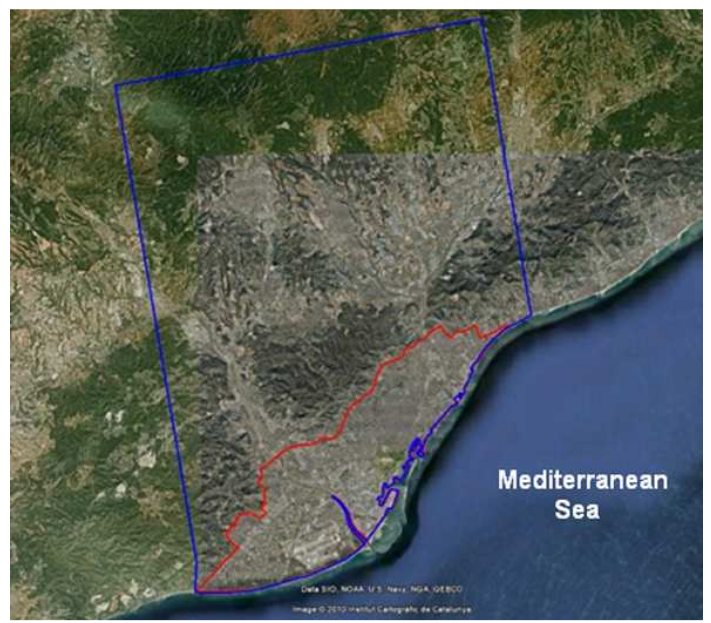

(a)

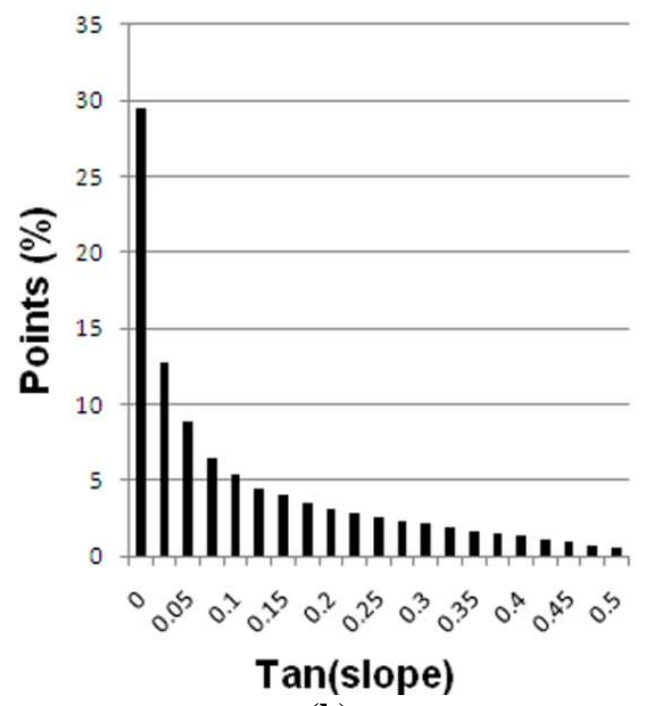

(b)

Figure 1. Barcelona test site (a) and frequency distribution of terrain inclination (b)

The large area (blue) contains mountainous terrain, and forested zones; the altitude spans from sea level up to more than $1000 \mathrm{~m}$. The Urban Area (red) is mostly flat, but it also contains some undulated built-up areas and the hill of Montjuïc, the main site of the Olympic Games in 1992. The maximum altitude inside the Urban Area is about $250 \mathrm{~m}$.

\section{DATA SETS}

In the study, two TSX StripMap mode images (Figure 2) were used for DSM generation by InSAR. The images were taken in 2009 and feature $3 \mathrm{~m}$ resolution and 11 days repeat-pass time interval. The ascending orbit images were taken in VV polarization. The normal orbital baseline between is $86.3 \mathrm{~m}$ which results in the 2PI ambiguity height of $64.2 \mathrm{~m}$.

In Stripmap mode TSX acquires long strips up to $1650 \mathrm{~km}$ length with $30 \mathrm{~km}$ swath width. The ground swath is illuminated with a continuous sequence of pulses while the antenna beam is fixed in elevation and azimuth. This results in an image strip with continuous image quality in azimuth (Roth 2003).
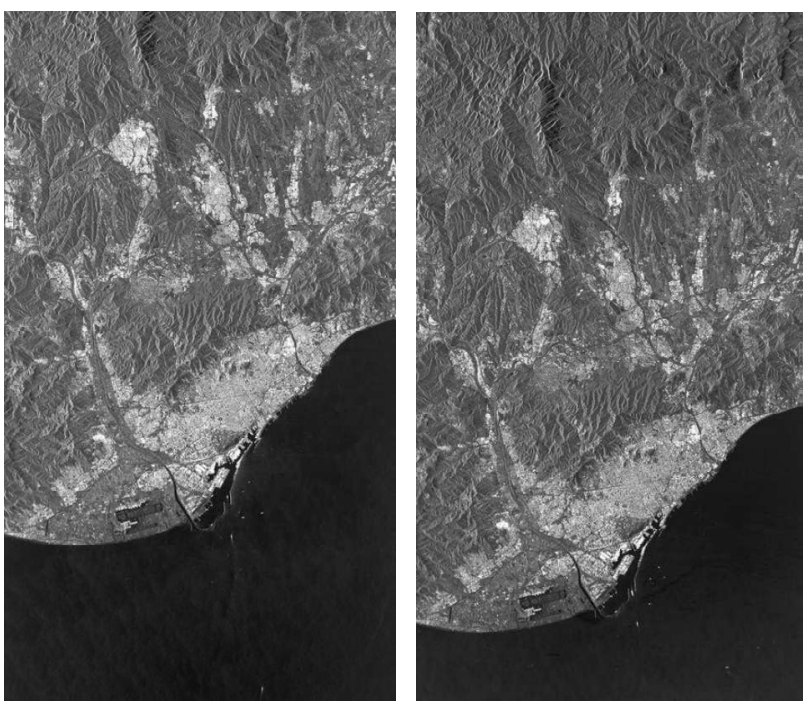

Figure 2. TSX StripMap mode image-pair (left: image 1, right: image 2)

The reference DTM of Barcelona was provided by the Cartographic Institute of Catalonia (Institut Cartogràfic de Catalunya, ICC), the official organization of surveying in Catalonia. It was achieved by large scale photogrammetry with $15 \mathrm{~m}$ grid spacing. The accuracy is in between $10 \mathrm{~cm}-1 \mathrm{~m}$. Figure 3 shows this reference DTM separately for large area and urban area in color scale. This DTM is named following as REFDTM.

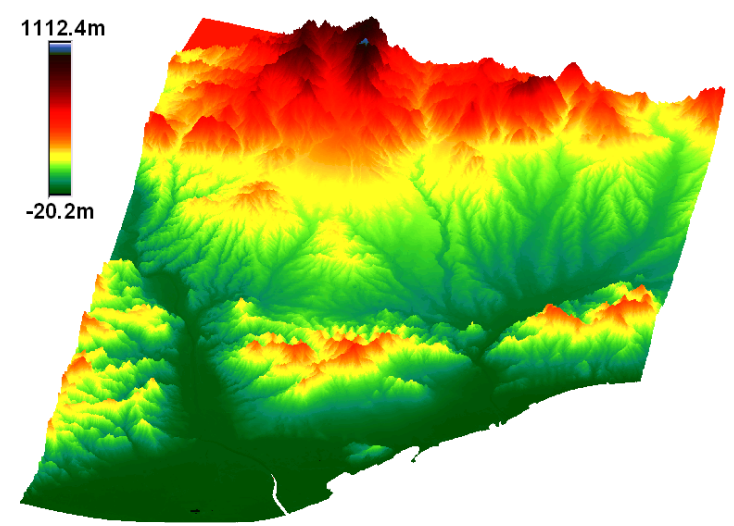

(a)

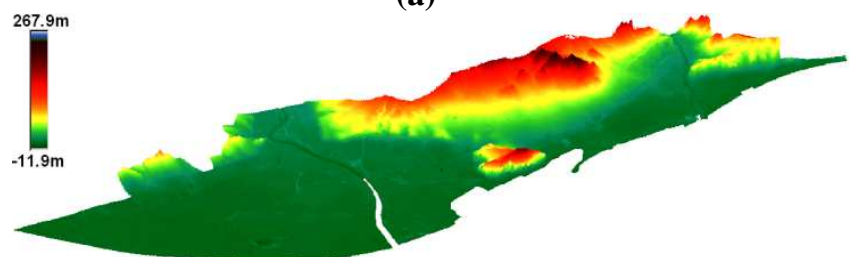

(b)

Figure 3. REFDTM of large area (a) and urban area (b) 


\section{DSM GENERATION BY INSAR DATA}

One major application of SAR is the generation of DSM. This task can be accomplished by various techniques, for instance, SAR Stereo (e.g., Raggam et al, 2010) or SAR Interferometry (e.g., Bamler and Hartl, 1998). In this study, a standard InSAR processing was conducted. This is quite different from optical stereoscopy. The processing consists of several complex steps such as co-registration, interferogram generation, flattening, filtering, coherence estimation, phase unwrapping, orbital refinement, phase to height conversion, and geocoding. Thereby, proper threshold values and other parameters have to be chosen to obtain good results, which were optimized during the investigation. We used the commercial software SARscape, which is an extension module of the ENVI package. We restrict ourselves to a summery here, more details about the processing can be found in Sefercik and Soergel (2010).

During InSAR processing, multi-looking by factor of 4 ( 2 both azimuth and range) was conducted and SRTM DEM was used as height reference to flatten the interferogram. This facilitates subsequent phase unwrapping due to the decreased phase gradients. Filtering according to Goldstein et al. (1998) was applied to denoise the interferogram before phase-unwrapping by region growing (Reigber, 1997) occurred. After that the unwrapped phase was converted to height and the generated DSM was averaged and geocoded onto $10 \times 10$ meter grid. Finally, the resulting DSM was cut into two areas mentioned in section 2. Large and urban area and a part from urban area (for better visualization of ground objects) can be seen sequentially in Figure 4 as a, b, and c.

\section{DEM VALIDATION}

The accuracy of a DEM can be assessed by various procedures. One of the common procedures is the comparison with a reference DEM (Lin et al. 1994). From this point of view, to perform the accuracy analysis, firstly DSM-DEM conversion was applied using filtering and smoothening by program RASCOR since the reference model is not a surface model but a terrain model. In the research, the entire validation process has been implemented by DEM evaluation software BLUH (Bundle Block Adjustment Leibniz University Hannover), developed by Dr. Karsten Jacobsen, Institute of Photogrammetry and Geoinformation (IPI), Leibniz University Hannover (Jacobsen, 2007) and program RASCOR is also part of BLUH.

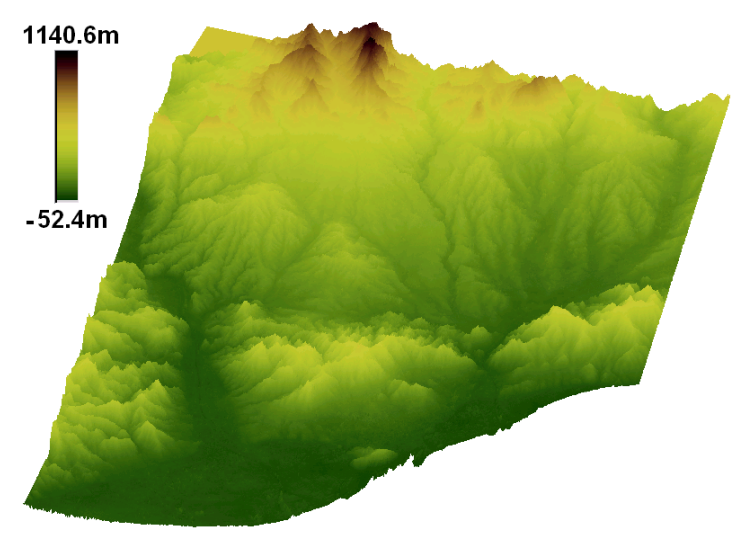

(a)

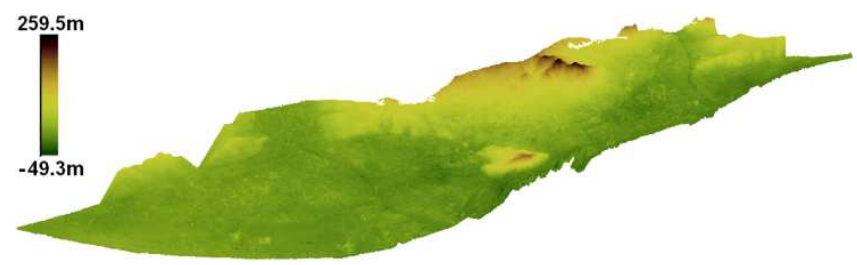

(b)

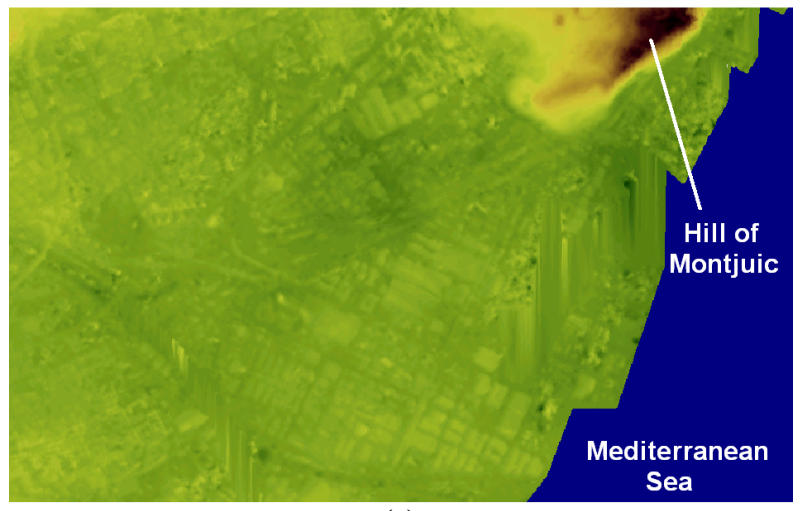

(c)

Figure 4. TSX DSM of large (a), urban (b) and a part of urban area $(\mathrm{c})$

Another crucial preprocessing step before accuracy validation is coregistration of evaluated and reference DEMs. Due to datum inconsistencies significant horizontal misalignment may arise that have to be eliminated. Therefore, the shifts between evaluated and reference DEMs were determined by adjustment with manual pre-correction and automatic shifting. The adjusted shifts and the root mean square (RMS) ' $\mathrm{Z}$ ' values before and after shifting process can be seen in Table 1 .

\begin{tabular}{|c|c|c|c|c|}
\hline \multirow[t]{2}{*}{ DEM } & \multirow{2}{*}{$\begin{array}{c}\text { Original } \\
\text { RMSZ } \\
{[\mathrm{m}]}\end{array}$} & \multicolumn{2}{|c|}{$\begin{array}{c}\text { Shift by } \\
\text { DEMSHIFT } \\
{[\mathrm{m}]} \\
\end{array}$} & \multirow{2}{*}{$\begin{array}{c}\text { RMSZ } \\
\text { after } \\
\text { Shifting } \\
{[\mathrm{m}]} \\
\end{array}$} \\
\hline & & $\mathbf{X}$ & $\mathbf{Y}$ & \\
\hline $\begin{array}{c}\text { TSX } \\
\text { Large } \\
\end{array}$ & 11.91 & 3.40 & 23.83 & 11.64 \\
\hline $\begin{array}{c}\text { TSX } \\
\text { Urban } \\
\end{array}$ & 9.02 & 19.86 & 27.88 & 8.59 \\
\hline
\end{tabular}

Table 1. Adjusted shifts between TSX DEM and REFDTM

After eliminating the planimetric mismatch the RMS height differences were calculated. The accuracy assessment is based on pixel wise height differences. The accuracy is also a function of terrain inclination. By this reason the accuracy has to be described by a constant value plus a constant value multiplied with the tangent of the terrain inclination $(\tan (\alpha))$. This relation is determined also by adjustment. At the validation the limit of height differences between TSX DEM and REFDTM is determined as ' $50 \mathrm{~m}$ ' on pixel base and the points which exceeds this threshold were eliminated automatically and called as 'Not Accepted Points' (NAP). The results of accuracy analysis are shown in Table 2.

\begin{tabular}{|c|c|c|c|}
\hline $\begin{array}{c}\text { REFERENCE } \\
\text { DEM }\end{array}$ & $\begin{array}{c}\text { EVALUATED } \\
\text { DEM }\end{array}$ & $\begin{array}{c}\text { ACCURACY } \\
(\mathbf{m})\end{array}$ & $\begin{array}{c}\text { NAP } \\
(\boldsymbol{\%})\end{array}$ \\
\hline REFDTM & TSX Large & $9.11+4.79 \times \tan (\alpha)$ & 0.00 \\
\hline REFDTM & TSX Urban & 8.66 & 0.00 \\
\hline
\end{tabular}

Table 2. Accuracy results of TSX DEMs 
Considering frequency distribution of terrain inclination (Figure 1-b) this table can be enlarged as follow,

\begin{tabular}{|c|c|c|c|}
\hline \multirow{2}{*}{ DEM } & \multicolumn{3}{|c|}{$\begin{array}{c}\text { ACCURACY } \\
\text { Related to Tan (slope)(m) }\end{array}$} \\
\cline { 2 - 4 } & $\mathbf{0}$ & $\mathbf{0 . 1}$ & $\mathbf{0 . 2}$ \\
\hline $\begin{array}{c}\text { TSX } \\
\text { Large }\end{array}$ & 9.11 & 9.59 & 10.07 \\
\hline $\begin{array}{c}\text { TSX } \\
\text { Urban }\end{array}$ & 8.66 & 8.66 & 8.66 \\
\hline
\end{tabular}

Table 3. Accuracy results depending upon the terrain inclination

As known, terrain inclination is one of significant facts for imaging systems. Looking on Table 3, it can be easily seen that the accuracy of TSX DEM at the large area is lower than urban area. This result shows us that steep and mountainous topography is also a problem for TSX StripMap mode data like previous SAR imaging sensors, for instance, SRTM (Koch and Heipke, 2001, Sefercik and Alkan, 2009). In general, the accuracy of DEM derived by TSX StripMap mode data is in between 8-10 meters depending up on the terrain inclination.

\section{PERSISTENT SCATTERER INTERFEROMETRY USING TSX DATA}

The persistent scatterer (PS) processing scheme used here is mainly based on the ideas presented in (Ferretti et al. 2000) and (Liu et al., 2009). It is essentially a two-step procedure. In a first step, the atmosphere is estimated with the help of a sparse network of very stable points. After removal of the atmosphere, the processing proceeds on a pixel by pixel basis employing a periodogram approach to estimate the height of the pixel under investigation. The main outcome for every pixel is its height and a quality measure called inter-image coherence, which is calculated from the phase residuals. Only pixels having an interimage coherence above a certain threshold are accepted as PS. In contrast to common practice, deformation has not been modeled in the very last step of the algorithm (i.e., the pixel wise processing). As a consequence, PS undergoing large deformations may have been rejected due to large phase residuals resulting in a low inter-image coherence. Furthermore, the accuracy of the height estimate of slowly moving PS is impaired due to the deformation phase essentially acting as additional phase noise. The used data stack consists of 24 TSX stripmap images of Barcelona extending over a timeframe of approximately 2 years (December 2008 to January 2011). The PSI processing was conducted in cooperation with Institut Cartogràfic de Catalunya (ICC).

At the evaluation of PS results, achieved from TSX data, 40 buildings were chosen from Barcelona test field and their heights were compared with Google Earth data derived by laser scanning. When obtaining building heights from Google Earth, the elevation of terrain was excluded. Figure 5 shows the selected buildings on Google Earth and the following Table 4 includes the results.

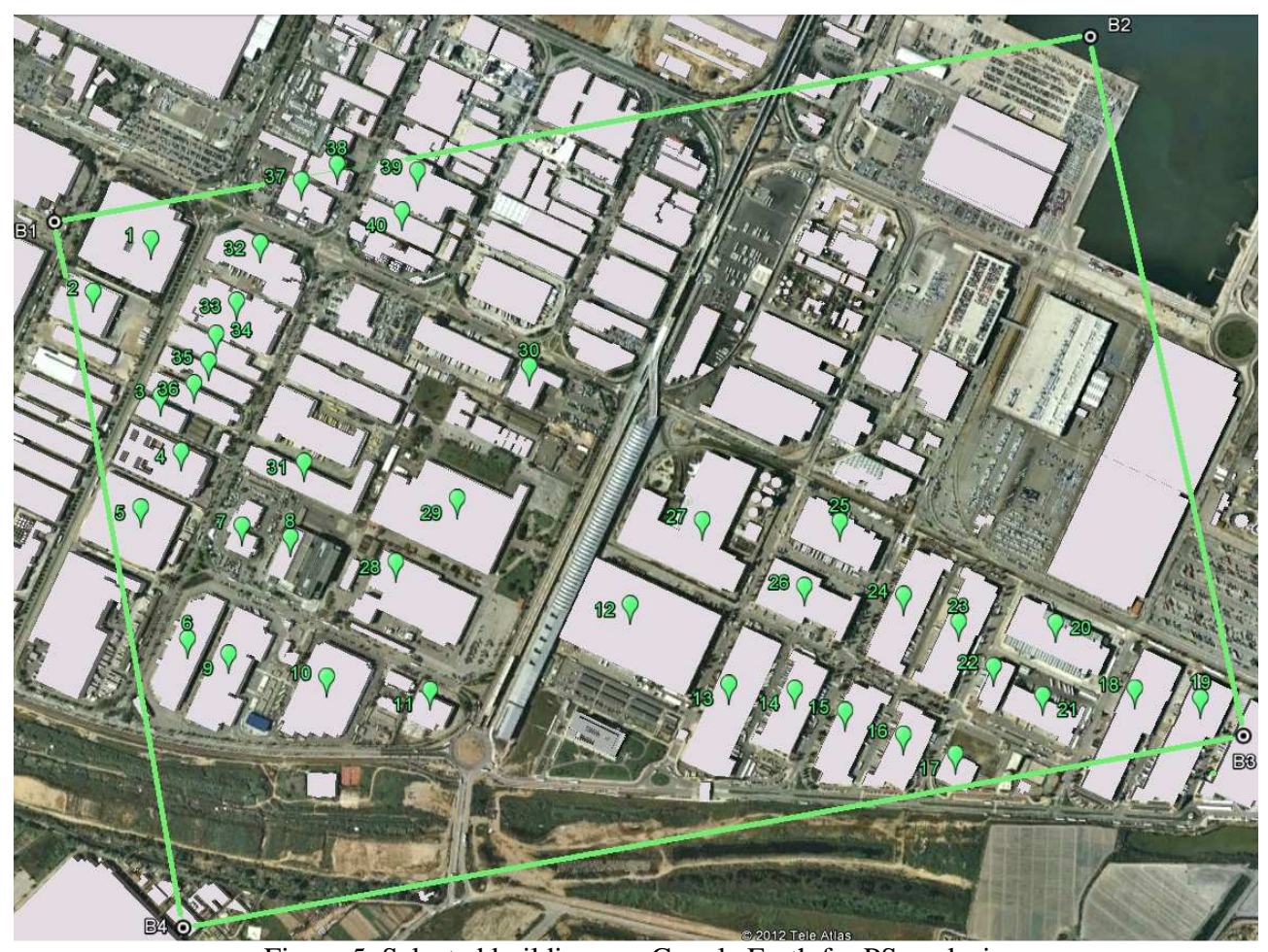

Figure 5. Selected buildings on Google Earth for PS analysis 
ISPRS Annals of the Photogrammetry, Remote Sensing and Spatial Information Sciences, Volume I-7, 2012 XXII ISPRS Congress, 25 August - 01 September 2012, Melbourne, Australia

\begin{tabular}{|c|c|c|c|c|c|c|c|c|}
\hline $\begin{array}{l}\text { Building } \\
\text { number }\end{array}$ & $\begin{array}{c}\text { Google } \\
\text { Earth (m) }\end{array}$ & $\begin{array}{l}\text { PS } \\
(\mathrm{m})\end{array}$ & $\begin{array}{l}\text { Difference } \\
\text { (m) }\end{array}$ & $\begin{array}{l}\text { Building } \\
\text { number }\end{array}$ & $\begin{array}{c}\text { Google } \\
\text { Earth (m) }\end{array}$ & $\begin{array}{l}\text { PS } \\
(\mathbf{m})\end{array}$ & $\begin{array}{c}\text { Difference } \\
\text { (m) }\end{array}$ & $\begin{array}{c}\text { RMSZ } \\
\text { (m) }\end{array}$ \\
\hline 1 & 12 & 11.85 & -0.15 & 21 & 10 & 8.21 & -1.79 & \multirow{20}{*}{2.58} \\
\hline 2 & 13 & 8.2 & -4.8 & 22 & 14 & 9.12 & -4.88 & \\
\hline 3 & 12 & 13.67 & 1.67 & 23 & 14 & 13.68 & -0.32 & \\
\hline 4 & 22 & 14.59 & -7.41 & 24 & 14 & 13.68 & -0.32 & \\
\hline 5 & 8 & 10.03 & 2.03 & 25 & 17 & 14.59 & -2.41 & \\
\hline 6 & 12 & 10.03 & -1.97 & 26 & 18 & 14.59 & -3.41 & \\
\hline 7 & 9 & 9.12 & 0.12 & 27 & 17 & 14.59 & -2.41 & \\
\hline 8 & 16 & 24.62 & 8.62 & 28 & 13 & 16.41 & 3.41 & \\
\hline 9 & 12 & 10.03 & -1.97 & 29 & 12 & 13.67 & 1.67 & \\
\hline 10 & 13 & 11.86 & -1.14 & 30 & 13 & 12.76 & -0.24 & \\
\hline 11 & 14 & 12.77 & -1.23 & 31 & 15 & 16.42 & 1.42 & \\
\hline 12 & 15 & 13.68 & -1.32 & 32 & 15 & 14.59 & -0.41 & \\
\hline 13 & 13 & 10.94 & -2.06 & 33 & 17 & 10.03 & -6.97 & \\
\hline 14 & 14 & 14.59 & 0.59 & 34 & 8 & 10.94 & 2.94 & \\
\hline 15 & 14 & 16.41 & 2.41 & 35 & 11 & 11.85 & 0.85 & \\
\hline 16 & 13 & 16.41 & 3.41 & 36 & 14 & 15.5 & 1.5 & \\
\hline 17 & 11 & 11.85 & 0.85 & 37 & 8 & 6.38 & -1.62 & \\
\hline 18 & 14 & 11.85 & -2.15 & 38 & 20 & 10.03 & -9.97 & \\
\hline 19 & 13 & Mismatch & - & 39 & 21 & 19.14 & -1.86 & \\
\hline 20 & 17 & 12.77 & -4.23 & 40 & 7 & 5.47 & -1.53 & \\
\hline
\end{tabular}

Table 4. Results of PS analysis

As can be seen on Table 4, the acquired PS values from TSX seem quite coherent with Google Earth data derived from laser scanning and the RMSZ of differences is around $2.5 \mathrm{~m}$. The buildings which have height difference more than $5 \mathrm{~m}$ against Google Earth reference data were marked as bold. These buildings (Figure 6) have irregular roof types and are represented by just one height value in Google Earth's prismatic building models which causes difficulties to compare with PS data.

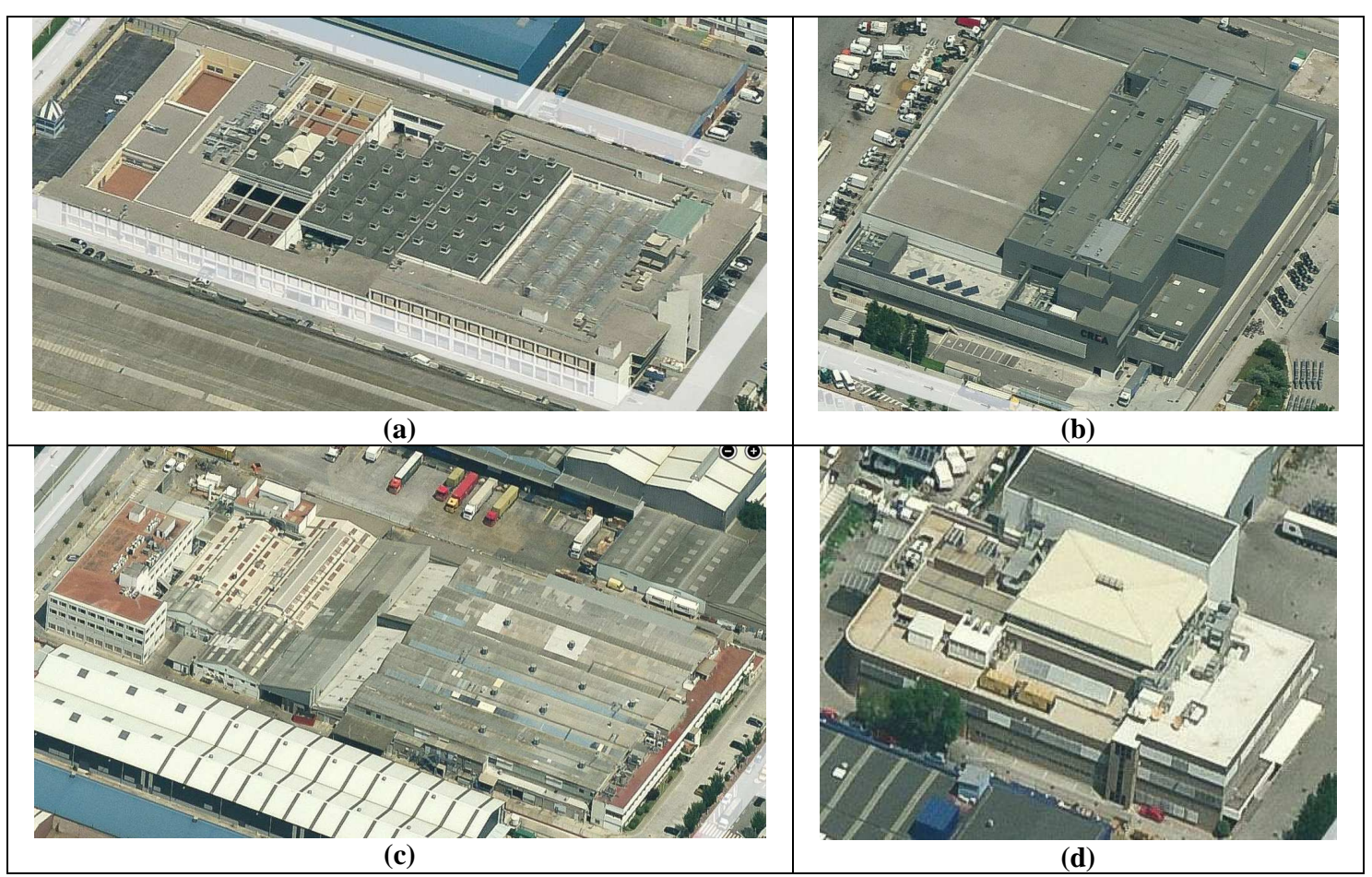

Figure 6. Oblique views of buildings 4 (a), 8 (b), 33 (c), and 38 (d) (Bing map, 2012 


\section{CONCLUSION}

In this research, the validation of digital elevation models and PS data derived from current SAR satellite TSX was targeted.

Towards this purpose, StripMap mode spatial data of TSX, acquired with $3 \mathrm{~m}$ resolution was employed and a digital surface model was generated in Barcelona, Spain, with $10 \mathrm{~m}$ grid spacing applying complex interferometric processing steps and validated in two separate areas including different terrain formations. One of these areas was large part of Barcelona with steep and mountainous topography reaches up to 1100 meter altitude. Other area was the urban part of the city with smoother terrain and the maximum altitude is $250 \mathrm{~m}$.

On the preparation step before accuracy analysis, DSMDEM conversion was applied by filtering and shifting was performed for horizontal overlapping of evaluated DEM and reference DEM.

As the result of analysis, it was seen that the accuracy of TSX StripMap mode DEM is better in urban area in comparison with large area as expected. And the DEM has $8-10 \mathrm{~m}$ accuracy in Barcelona test field depending upon the terrain slope.

The acquired PS values from TSX seem quite coherent with Google Earth data derived by laser scanning and the RMSZ of differences is around $2.5 \mathrm{~m}$.

\section{ACKNOWLEGMENTS}

Thanks are going to DLR (German Aerospace Center), Germany, for providing about 85 TerraSAR-X images of built up regions without any cost in the framework of the project LAN0634. We thank the Institut Cartogràfic de Catalunya (ICC) for support in many ways. In the framework on an cooperation the PSI processing was conducted using ICC's approach. Furthermore, ICC provided the reference DTM of Barcelona.

\section{REFERENCES}

Bamler, R., Hartl, P. 1998. Synthetic aperture radar interferometry. Inverse Problems, Vol. 14, No. 4, R1R54.

Ferretti, A., Prati, C., Rocca, F., 2000. Nonlinear Subsidance Rate Estimation Using Permanent Scatterers in Differential SAR Interferometry. IEEE Transactions on Geoscience and Remote Sensing 38(5), pp. 2202-2212.

Goldstein, R.M., Werner, C.L. 1998 Radar interferogram filtering for geophysical applications. Geophysical Research Letters, Vol. 25, No. 21, pp. 4035-4038.

ISPRS Working Group VII/2 - SAR Interferometry. http://www.commission7.isprs.org/wg2/ (accessed 15 Apr. 2012)

Jacobsen, K., (2003). DEM Generation from Satellite Data. EARSeL Workshop, 5-7th June, Ghent, Belgium, pp. 273-276.
Jacobsen, K. 2007. Orientation of high resolution optical space images, ASPRS annual conference, Tampa, CD, 9 p.

Koch, A., Heipke, C. 2001. Quality Assessment of Digital Surface Models Derived From the Shuttle Radar Topography Mission (SRTM). IEEE 2001 International Geoscience and Remote Sensing Symposium, University of New South Wales, 9-13th July, Sydney (Australia).

Lin, Q., Vesecky, J. F., Zebker, H. A. 1994. Comparison of elevation derived from InSAR data with DEM over large relief terrain. International Journal of Remote Sensing, Vol: 15, pp.1775-1790.

Liu, G., Buckley, S. M., Ding, X., Cheng, Q. , Luo, X., 2009. Estimating Spatiotemporal Ground Deformation With Improved Permanent Scatterer Radar Interferometry", IEEE Transactions on Geoscience and Remote Sensing. 47 (8), pp. 2762-2772.

Rabus, B., Eineder, M., Roth, A., Bamler, R. 2003. The Shuttle Radar Topography Mission - A new class of digital elevation models acquired by spaceborne radar. ISPRS Journal of Photogrammetry and Remote Sensing, Vol. 57, No. 4, pp. 241-262.

Raggam, H., Gutjahr, K. H., Perko, R., Schardt, M. 2010. Assessment of the Stereo-Radargrammetric Mapping Potential of TerraSAR-X Multibeam Spotlight Data. IEEE Transactions on Geoscience and Remote Sensing, Vol. 48. No. 2. pp 971-977.

Reigber, A., Moreira, J. 1997. Phase unwrapping by fusion of local and global methods. International Geoscience and Remote Sensing Symposium (IGARSS), Singapore, Vol. 2, pp. 869-871.

Roth, A. 2003. TerraSAR-X: A new perspective for scientific use of high resolution space-borne SAR data, 2nd GRSS/ISPRS Joint Workshop on "Data Fusion and Remote Sensing over Urban Areas, 22-23 May, Berlin, Germany

Sefercik, U., Alkan, M. 2009. Advanced analysis of differences between $\mathrm{C}$ and $\mathrm{X}$ bands using SRTM data for mountainous topography, Journal of the Indian Society of Remote Sensing, Springer, ISSN: 0255-660X (Print) 0974-3006 (Online), Press: DOI: 10.1007/s12524-0090044-4, Pages: 335-349.

Sefercik, U., Soergel, U. 2010. Comparison of High Resolution InSAR and Optical DEMs. EARSeL Joint SIG Workshop: Urban - 3D - Radar - Thermal Remote Sensing and Developing Countries, Ghent, CD, 13 p. 